\title{
Mini-thoracotomy in redo mitral valve surgery: safety and efficacy of a standardized procedure
}

\author{
Filippo Prestipino ${ }^{1}$, Riccardo D’Ascoli ${ }^{1}$, Ádám Nagy $^{2}$, Gianluca Paternoster ${ }^{3}$, Erica Manzan ${ }^{1}$, \\ Giampaolo Luzi ${ }^{1}$ \\ ${ }^{1}$ Cardiac Surgery Unit, AOR San Carlo Hospital, Basilicata, Italy; ${ }^{2}$ Károly Rácz School of PhD Studies, Semmelweis University, Budapest, Hungary; \\ ${ }^{3}$ Cardiac Anaesthesia and Cardiac-Intesive Care, AOR San Carlo Hospital, Basilicata, Italy \\ Contributions: (I) Conception and design: F Prestipino, Á Nagy; (II) Administrative support: None; (III) Provision of study materials or patients: \\ None; (IV) Collection and assembly of data: F Prestipino, R D'Ascoli, G Paternoster, E Manzan; (V) Data analysis and interpretation: F Prestipino, \\ G Luzi; (VI) Manuscript writing: All authors; (VII) Final approval of manuscript: All authors. \\ Correspondence to: Filippo Prestipino, MD. Cardiac Surgery Unit, AOR San Carlo Hospital, Basilicata, Italy. Email: filippo.prestipino@libero.it.
}

Background: Re-operative mitral valve surgery is sometimes burdened by a greater technical difficulty and a higher complications rate than the first operation. Minimally invasive cardiac surgery has become routine, and it could significantly reduce the surgical risk in redo surgery. The objective of our retrospective observational study is to assess the results of cardiac reoperations in patients with mitral valve disease approached trough a 5-7 cm right mini-thoracotomy.

Methods: From February 2017 to December 2019, 65 patients underwent re-operative mitral valve surgery in our institution. Cardiopulmonary bypass (CPB) was started by cannulation of the femoral and jugular vein and femoral artery or alternatively right axillary artery. Patients enrolled had a mean age of $66.6 \pm 11.5$ years. Patients were divided into three groups based on the procedure adopted: external aortic cross-clamp (EAC), EndoAortic balloon occlusion (EABO) and ventricular fibrillation (VF). Major complications were evaluated and compared with a propensity matched population of patients undergoing elective isolated mitral valve surgery via right minithoracotomy (MVS).

Results: The average time between last operation and reoperation was $7.1 \pm 3.4$ years. Fourteen patients (21\%) underwent mitral valve repair and 51 patients (78\%) underwent mitral valve replacement; 9 patients (14\%) received tricuspid valve surgery. There was no statistically significant difference in CPB time between the groups. Seven patients $(11 \%)$ had a postoperative renal failure, 5 patients $(8 \%)$ underwent surgical reopening for bleeding; incidence of post-operative stroke and pace-maker implantation was $3 \%$ for both. No deaths were registered during in-hospital stay and at 30-days echocardiographic control all patients respect the criterions of device success according with MVARC. Propensity matched patients of group redo had a longer $\mathrm{CPB}$ time $(100.8 \pm 42.7$ versus $72.8 \pm 16.7 \mathrm{~min}, \mathrm{P}<0.001)$ and cross-clamp time $(71.9 \pm 30.7$ versus $59 \pm 10.7 \mathrm{~min}, \mathrm{P}<0.001)$ respect to first operation mitral valve surgery patients.

Conclusions: Minimally invasive mitral valve redo surgery is a safe procedure. Less invasive techniques in redo surgery could minimize morbidity and mortality without prolonging the duration of CPB.

Keywords: Mitral valve repair; mitral valve replacement; mini-thoracotomy; redo surgery

Submitted Apr 15, 2021. Accepted for publication Aug 06, 2021.

doi: $10.21037 /$ jtd-21-667

View this article at: https://dx.doi.org/10.21037/jtd-21-667

\footnotetext{
$\wedge$ ORCID: 0000-0002-4668-0633.
} 


\section{Introduction}

Over the last decades, the evolution in cardiac surgery has resulted in better comfort for patients, represented by reduced blood loss, less pain, lower morbidity and shorter recovery time. This objective has been achieved through the development of minimally invasive procedures. Minithoracotomy for mitral valve surgery has obtained a large consensus in cardiac surgeons because of optimal results and good reproducibility (1). In a well-experienced center for minimally invasive surgery, redo mitral valve surgery (RMVS) can be approached with right mini-thoracotomy, ensuring a better mitral valve view and avoiding the complications of iterative sternotomy (2). After an initial learning curve, the higher technical complexity is balanced by improved outcome for the patients (3).

We present the following article in accordance with the STROBE reporting checklist (available at https://dx.doi. org/10.21037/jtd-21-667).

\section{Methods}

\section{Population in study}

From February 2017 to December 2019, 65 patients underwent RMVS in our institution. In 30 patients' aorta was clamped by using an endo-aortic balloon occlusion device (EABO), in 5 patients' continuous perfusion under ventricular fibrillation (VF) was established and 30 patients underwent direct external aortic cross clamping (EAC). A retrospective analysis was performed using clinical data obtained from a prospective database updated concomitantly with patient discharge data. This study was conducted in accordance with the Declaration of Helsinki (as revised in 2013). The Regional Unique Ethical Committee approved the use of these data for research (CEUR Registry Number 652021, ID 20210028661, approval received in data 20/07/2021) and informed consent was obtained from all patients. In all patients, the first operation had been performed via full median sternotomy. In patients who had undergone previous replacement of ascending aorta or previous bypass grafts direct aortic cross-clamping was preferentially avoided.

Composite of 30-day major complications was based on MVARC criteria and consisted of 30-day mortality, conversion to sternotomy, myocardial infarction, stroke, renal injury AKIN class II-III, any surgical re-intervention (e.g., bleeding, empyema or failed repair), prolonged ventilation $>48$ hours, low cardiac output syndrome (LCOS)
$>48$ hours or necessity for mechanical Low cardiac output syndrome. LCOS was defined as the necessity for inotropes $>30$ min after correcting for fluid which we separated in three categories: requiring $<48$ hours of support, requiring $>48$ hours of support and requiring mechanical support (4). The primary end-point was incidence of post-operative major complications including 30-day post-operative mortality. The secondary end-point was 30 -day procedural success, according to MVARC echocardiographic criterions, that include: reduction of mitral regurgitation (MR) to either optimal or no more than moderate, without significant stenosis (EROA $>1.5$ with trans-mitral gradient $<5 \mathrm{mmHg}$ ) and with no greater than mild paravalvular MR or associate hemolysis. The median duration of followup was 12.5 months [interquartile range (IQR), 5.5 to 25.75 months], follow-up was completed at $100 \%$.

\section{Surgical technique}

The common clinical scenarios for reoperative mitral surgery include patients with native mitral valve structural or functional disease (stenosis, regurgitation or both) after previous non-mitral surgery (coronary artery bypass grafting, aortic valve replacement, aortic root or ascending aorta replacement, congenital septal defects or anomalies) or patients undergoing a second or further procedure on the mitral valve after previous failed repair or replacement (malfunctioning, detachment, thrombosis, degeneration) (5). The surgical technique routinely adopted in our institution for mini-thoracotomy requires that the patient is placed supine on the operating table with the right arm abducted and the elbow at $45^{\circ}$ by using an air sac under the right scapula and partially insufflated on purpose to obtain a better distancing of the ribs. Cardiopulmonary bypass $(\mathrm{CPB})$ is generally established by percutaneous cannulation of the jugular vein and surgical cannulation of the femoral artery and femoral vein. This procedure is performed under echocardiographic guidance. In the case of peripheral arteriopathy, the right axillary artery, exposed with a surgical sub-clavicular approach, is preferred for arterial perfusion, ensuring antegrade perfusion. Preoperative cardiosynchronized multi-detector computed scan tomography (MDCT) with aorto-femoral angio-CT is performed to screen all patients for coronary arteries integrity, chest anatomy; aortopathy and peripheral arteriopathy when diagnosed may contraindicate peripheral arterial cannulation. Chest skin incision is performed at the level of the fourth intercostal space between the anterior and 

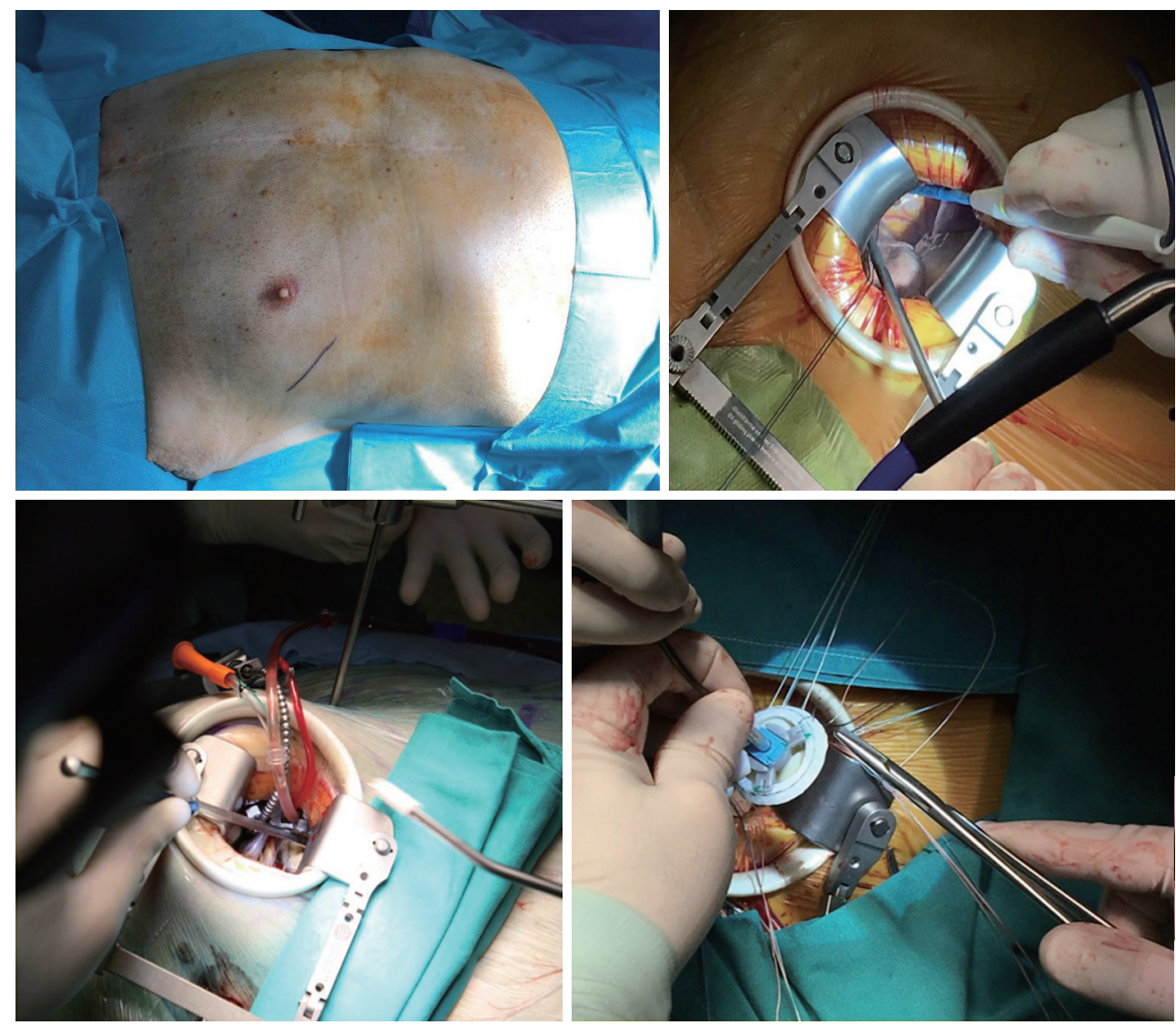

Figure 1 Different stages of mitral valve surgery by mini-thoracotomy. Upper left image: skin incision mark. Upper right: exposition of aorta, right atrium, interatrial groove. Lower left: left atriotomy after aortic clamping and cardioplegia delivering. Lower right: mitral valve prosthesis suture.

middle axillary line, the intercostal muscle is opened and an Alexis Wound retractor (Applied Medical) is positioned with a rib-retractor (see Figure 1). Extracorporeal circulation is started and lung collapsed; when possible the pericardium is opened 1-2 cm above the phrenic nerve and suspended, after having lysed adhesions if any. The surgical field is flooded with carbon dioxide at a flow rate of $2 \mathrm{~L} / \mathrm{min}$. The aorta is identified and dissected posteriorly and anteriorly to allow positioning of aortic clamp. A Y-shape ventcardioplegia catheter is placed in the proximal ascending aorta and clamping is performed through the transverse sinus using a Cygnet clamp (Novare Surgical System INC, Cupertino, CA, USA). Crystalloid cardioplegia sec. Custodiol is delivered in a single dose. When it is not possible to clamp the aorta via right mini-thoracotomy, $\mathrm{EABO}$ is preferred, while when $\mathrm{EABO}$ is not applicable, for example for ascending aorta dilation or descending aorta unfavorable anatomy, or in presence of pervious coronary grafts, continuous coronary perfusion and hypothermic $\mathrm{VF}$ is adopted as alternative solution. In case of EABO implantation, the favorite site of cannulation is right femoral artery exposed surgically adopting the Endoreturn cannula (Edwards Lifesciences), aortic balloon clamp (IntraClude device - Edwards Lifesciences) is advanced on guide-wire in the aorta with trans-esophageal echography (TEE) assistance and it is positioned in ascending aorta near sino-tubular junction. As regards operations performed in $\mathrm{VF}$, continuous aortic perfusion is provided in a standard fashion via femoral artery, systemic hypothermia at 30 degrees Celsius is established and VF is induced by and electrical fibrillator positioned on right ventricle; in these cases, aortic valve competence is mandatory and bypass grafts when present are left unclamped. The left superior pulmonary vein is identified and the left atrium is opened 
with incision in the Sondergaard's groove extended on the roof of the left atrium; in alternative if reaching left atrium is technically demanding, the right atrium is opened and the mitral valve was exposed trough incision of the fossa ovalis, as described by some authors (6). The mitral valve is exposed using a retractor passed through the anterior chest wall and held in place by a pneumatic arm. In degenerative mitral regurgitation, when the repair of the mitral valve is technically possible, we usually use the "respect" technique and neo-chordae implantation. An annuloplasty ring made of a Gore-Tex vascular graft $6 \mathrm{~mm}$ configured for pediatric shunt was sutured on the posterior annulus to complete the mitral valve repair. In the others mitral pathologies, the kind of repair and the choice of ring prostheses depends on the peculiar anatomy and etiology of the mitral incompetence. In case of mitral valve replacement, the subvalvular apparatus is preserved whenever possible; pledgeted $U$ sutures are placed into the annulus and the mitral prosthesis is locked with the help of automated titanium fasteners (Cor-knot, LSI Solutions). The majority of patients included in our study had just undergone mitral valve repair or replacement, which is the reason for the low percentage of mitral valve repairs performed; we repaired all mitral degenerative valves in the cohort as suggested by international best practice guidelines $(7,8)$. When surgery on the tricuspid valve is required, an oblique right atriotomy is performed and the tricuspid valve is exposed by suspending the atrium wall with stay sutures; tricuspid valve incompetence is usually repaired by annuloplasty ring implantation when cusps are preserved. Tricuspid valve surgery was performed in the case of severe pathology, as suggested by guidelines, and repair is planned for tricuspid severe incompetence associated with a dilated annulus $>40 \mathrm{~mm}$ or $21 \mathrm{~mm} / \mathrm{m}^{2}$ in $2 \mathrm{D}$ echography (9). At the end of surgery on the valve the atriotomy is closed, followed by deairing, then the aortic clamp is removed; CPB is gradually discontinued. Hemostasis and chest closure are performed in a standard fashion.

\section{Statistical analysis}

Data were analyzed using IBM SPSS statistical software version 25.0 (SPSS, Armonk, New York, USA; 2012) and STATA Statistics/Data Analysis (Stata-Corp 16.0, College Station, Texas, USA; 2013). Continuous variables are reported as mean values with standard deviation; percentages and frequencies were used for categorical variables. The mean age was $66.6 \pm 11.5$ years (range, $49-79$ years). The average time between the last operation and reoperation was $7.1 \pm 6.4$ years. The majority of patients were moderately or strongly symptomatic, New York Heart Association functional class II to IV (50 patients, 77\%). The mean left ventricle ejection fraction (LVEF) was $51 \% \pm 10.5 \%$. The mean Euroscore II was 3.1 \pm 5.8 . Data regarding pulmonary artery mean pressure (PAPS), comorbidities and type of previous cardiac intervention are summarized in Table 1. Patients were divided into three groups based on the procedure adopted: External aortic cross-clamp (EAC), EndoAortic balloon occlusion (EABO) and VF. Postoperative outcome and incidence of major complications are resumed on Table 2. Considering the rate of major complications, it was decided to perform a propensity match of RMVS patients with a population of patients undergoing elective isolated mitral valve surgery via right minithoracotomy (MVS). The validity of the propensity score model was confirmed by the C statistic (C 1/4 0.83). The balance between the groups was reconfirmed by calculating the standardized differences for each variable after matching (all 10\%). A multivariate logistic regression model was used to assess the influence of re-operation on the diverse outcome parameters. The previously calculated propensity score was then included into the model. Thus, adjusted odds ratios and $\mathrm{P}$ values could be obtained.

\section{Results}

Fourteen patients $(21 \%)$ with mitral regurgitation owing to posterior prolapse/flail underwent mitral valve repair by implantation of a pair of neo-chordae devices on P2 and posterior annuloplasty by a Gore-Tex band. Fiftyone patients $(78 \%)$ underwent mitral valve replacement: 42 biological (82\%) and 9 mechanical prosthesis (18\%). Nine patients (14\%) received tricuspid valve surgery: of these patients, annuloplasty with an Edwards Tricuspid Physio ring was performed in 7 patients $(77 \%)$ and 2 patients $(23 \%)$ had a tricuspid valve replaced with a bioprosthesis. The type of prosthesis implanted was always determined by the criterions of patient's age, specific patient desire, comorbidities or any contraindications for anticoagulation therapy. We registered $0 \%$ of intraoperative conversion to sternotomy. The mean crossclamp time (excluding patients in VF) was $71.9 \pm 30.7 \mathrm{~min}$ and the mean CPB time was $100.8 \pm 42.7$ min (Table 2). There was no statistically significant difference in $\mathrm{CPB}$ time between the groups EAC, EABO and VF. Seven patients $(11 \%)$ had a postoperative temporary renal failure 
Table 1 Pre-operative data

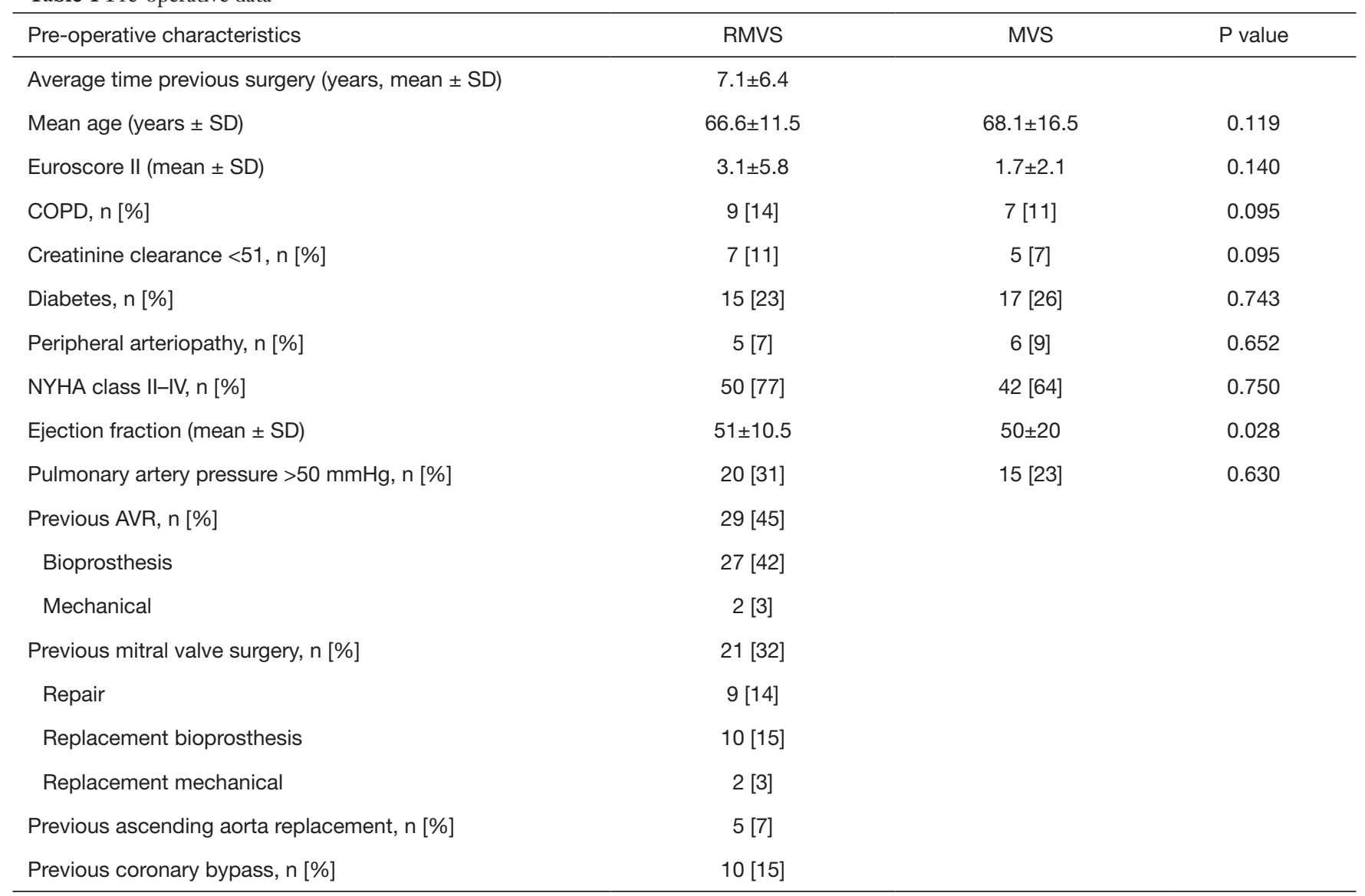

COPD, chronic obstructive pulmonary disease; AVR, aortic valve replacement; RMVS, reoperative minithoracotomy mitral valve surgery; MVS, minithoracotomy mitral valve surgery.

requiring continuous veno-venous hemofiltration $(\mathrm{CVVH})$, 3 patients in the EAC group, 3 patients in the EABO group and 1 patient in VF group. After this variable period of renal replacement, all these patients had their renal function restored. Five patients (8\%) underwent surgical reopening for bleeding, 2 in EAC group and 3 in EABO group; in urgent chest reopening, we have preferred to enlarge the mini-thoracotomy when required, rather than perform a new re-sternotomy, and in all cases the bleeding was resolved. Neurological events, understood with the definition of stroke, had an incidence of $3 \%$ : there weren't neurological post-operative events in the group of EAC, there was a patient with left parieto-temporal stroke in the group of $\mathrm{EABO}$ and a patient with cerebellar stroke in the group of VF. Incidence of post-operative pace-maker implantation was $3 \%$, two patients in the EABO group required electrical stimulation both for a low-frequency atrial fibrillation (Table 3). No deaths were registered during in-hospital stay. The mean intensive care unit (ICU) stay was 4 days (IQR, 1-7 days), in-hospital full stay was 9 days (IQR, 7-21 days), without significant difference between the tree groups of patients. At 30-day echocardiographic control all patients respect the criterions of device success according with MVARC. Propensity matched patients of group RMVS had a longer CPB time $(100.8 \pm 42.7$ versus $72.8 \pm 16.7 \mathrm{~min}, \mathrm{P}<0.001)$ and cross-clamp time $(71.9 \pm 30.7$ versus $59 \pm 10.7 \mathrm{~min}, \mathrm{P}<0.001)$ respect to MVS patients. Red blood cells (RBC) transfusion volume in intensive care unit (ICU) showed a significant difference $(258 \pm 431$ versus $751 \pm 885 \mathrm{~mL}, \mathrm{P}<0.001)$. The mortality, hospital and intensive care unit stay, temporary inotropic drug support need, pace-maker implantation rate, incidence of stroke and thromboembolic complications, renal failure, atrial fibrillation showed no significant difference between the 
Table 2 Intra-operative data

\begin{tabular}{|c|c|c|c|}
\hline Intra-operative characteristics & RMVS & MVS & $P$ value \\
\hline Mitral valve replacement, n [\%] & $51[78]$ & $4[6]$ & \\
\hline Biological & $42[82]$ & $4[6]$ & \\
\hline Mechanical & 9 [18] & 0 & \\
\hline Repair & $7[11]$ & 0 & \\
\hline Replacement & $2[3]$ & 0 & \\
\hline Combined procedure, $\mathrm{n}[\%]$ & $8[13]$ & 0 & \\
\hline Conversion to sternotomy, $\mathrm{n}[\%]$ & 0 & 0 & \\
\hline \multicolumn{4}{|l|}{ Arterial cannulation, n [\%] } \\
\hline Axillary & $5[7]$ & 6 [9] & \\
\hline Aortic & $1[3]$ & 0 & \\
\hline \multicolumn{4}{|l|}{ Venous cannulation, $\mathrm{n}[\%]$} \\
\hline Femoral & 65 [100] & $65[100]$ & \\
\hline Jugular & 65 [100] & 0 & \\
\hline Extracorporeal circulation time (mean \pm SD) & $100.8 \pm 42.7$ & $72.8 \pm 16.7$ & 0.001 \\
\hline Cross-clamp time (mean $\pm \mathrm{SD})$ & $71.9 \pm 30.7$ & $59 \pm 10.7$ & 0.001 \\
\hline
\end{tabular}

RMVS, reoperative minithoracotomy mitral valve surgery; MVS, minithoracotomy mitral valve surgery.

two groups. The overall 30 -day survival was $97 \%$ in the RMVS group and $98.5 \%$ in the MVS group. The causes of death were low-cardiac output syndrome in 2 patients in RMVS group and hepato-renal syndrome in 1 patient in MVS group.

\section{Discussion}

In literature was reported that a minimally invasive surgical approach through a right-sided mini-thoracotomy is a valid alternative to a repeated conventional median sternotomy $(10,11)$. Several technical options have been proposed for minimally invasive mitral reoperations, particularly regarding cannulation sites and use of classical aortic clamping, endoclamp or unclamped aorta (beating heart or VF) as well as the optimal temperature range $(12,13)$. In recent years, percutaneous trans-catheter or hybrid procedures are amplifying treatment spectrum in this selected cohort of patients (14-17). A recent metaanalysis by Daemen et al. about re-operative mitral valve surgery found a lower bleeding risk and a shorter length of hospital stay with mini-thoracotomy access compared with full sternotomy, whereas risk of stroke appeared to be comparable in the two groups. Right mini-thoracotomy allows the surgeon to use a different access with respect to the first operation, with the possibility to work in virgin tissues, avoiding the risk of injury owing to dissection of cardiac structures. In redo patients the right ventricle is often adherent to the inferior table of the sternum and it can be injured during re-sternotomy; to dissect the aorta from pulmonary artery to allow cross-clamping are dangerous, especially in the presence of frail tissues; more tissue dissected means higher bleeding risk. Furthermore, in patients which have already been operated of coronary bypass, patent grafts are potentially at risk of injury during chest opening. With a lateral approach through right minithoracotomy it could be avoided these situations. We preferred to use EABO for patients with aorto-coronary patent grafts, while VF is preferred when a patent mammary graft is present. Direct EAC and EABO are both safe 
Table 3 Post-operative data

\begin{tabular}{|c|c|c|c|}
\hline Post-operative findings & RMVS & MVS & $P$ value \\
\hline Myocardial infarction, n [\%] & 0 & 0 & \\
\hline Stroke, n [\%] & $2[3]$ & $1[1.5]$ & 0.142 \\
\hline AKI, n [\%] & $7[11]$ & $5[8]$ & 0.095 \\
\hline Prolonged ventilation, $\mathrm{n}[\%]$ & $12[18]$ & $11[17]$ & 0.752 \\
\hline Low cardiac output syndrome, $\mathrm{n}$ [\%] & $5[8]$ & $4[6]$ & 0.651 \\
\hline \multicolumn{4}{|l|}{ Echocardiographic parameters at 30 po days, $n$ [\%] } \\
\hline Severe mitral stenosis/regurgitation & 0 & 0 & \\
\hline Red blood cells transfusion volume, $\mathrm{mL}$ (mean $\pm \mathrm{SD}$ ) & $751 \pm 885$ & $258 \pm 431$ & 0.001 \\
\hline Permanent pace-maker implantation, n [\%] & $2[3]$ & $1[1.5]$ & 0.028 \\
\hline \multicolumn{4}{|l|}{ Intensive care unit stay, days (median, IQR) } \\
\hline \multicolumn{4}{|l|}{ In-hospital stay, days (median, IQR) } \\
\hline Renal replacement therapy, $\mathrm{n}[\%]$ & 7 [11] & $5[8]$ & 0.095 \\
\hline Temporary & 7 [11] & 5 [8] & 0.095 \\
\hline Permanent & 0 & 0 & \\
\hline
\end{tabular}

procedures with comparable complication rates (18); EAC requires a more accurate tissue dissection and may be less effective in the case of aorto-coronary patent grafts. The EABO procedure requires multidisciplinary co-operation involving an anesthesiologist and an echocardiographist in addition to the surgeon; the literature is controversial about the possibility that EABO can increase embolic or dissection risk, especially in patients with atherosclerotic aortic lesions. On the other hand, VF with mild hypothermia can be used to perform mitral redo surgery in selected patient with calcified aorta or severe peripheral disease (19). The best strategy for each patient depends on the preoperative characteristics and instrumental findings; a careful analysis of these is crucial for a successful outcome. Expertise in minimal invasive cardiac surgery can lead to a drastic reduction of complications and increased tolerability of the procedure (20). Critics of the minimally invasive approach for re-operative surgery, according to several studies, have reported longer CPB times, increased risk of cerebrovascular events and suboptimal exposure, which could compromise technical results (21). In our study, the $\mathrm{CPB}$ time may be considered aligned compared with data reported in the literature for mitral reoperations with a sternotomy approach $(22,23)$ and no patient required conversion to sternotomy because of technical difficulties or poor exposition. We really think that mitral valve can be better exposed with a lateral access rather than sternotomy. The incidence of post-operative cerebrovascular events related to direct aortic cross clamp and retrograde perfusion is also comparable to elective first time mitral valve minimally invasive surgery. Embolic events imputed to femoral retrograde perfusion can be avoided with a preoperative estimate of the risk with CT imaging $(24,25)$; in case of higher embolic risk, the right axillary artery cannulation can be a solution (26). Stroke rate in literature range from $0 \%$ of Murzi and coll to $5.8 \%$ of Ricci and coll. We speculate that the incidence of complications reported in the literature for redo right mini-thoracotomy mitral valve surgery could be overestimated, without taking into account improvement of technical devices and surgeons 
expertise (27). Mortality rates reported in literature varied from $11 \%$ of Conn in 2004 to $3 \%$ of Arcidi and coll. in 2014 (28-30). The mortality reported in our trial and the incidence of complications are very encouraging, suggesting that minimally invasive surgery should be performed for all patients undergoing mitral re-operative surgery.

\section{Conclusions}

Minimally invasive mitral valve redo surgery via right mini-thoracotomy might be a safe and effective procedure without an increase in CPB time. An experienced center and adequate surgeons training are necessary requirements to perform a standardized procedure, obtaining satisfactory results. Limitations related with the mini-thoracotomy approach for re-operative mitral valve surgery are various, such as the learning curve, that allow only a few number of surgeons to perform this kind of surgery, and the infrequence of this group of surgical patients is not conducive to the improvement of "surgical teaching". Another criticism is that respect to full-sternotomy, minithoracotomy exposes the patient to a higher risk of airembolism, linked to the small exposure of cardiac cavities; it may be reduced by insufflation of $\mathrm{CO}_{2}$ in the chest cavity, that we perform routinely. Furthermore, limitations related to the VF approach are hypothermia complications and cerebral embolism; for these reasons, we reserve this approach to the patients in which no other possibilities are allowed (EAO or EABO). However, despite the limits described, less invasive techniques in redo surgery may reduce bleeding, intensive care unit stay, and total length of stay, improving the rapid recovery in complex pathology and fragile patients, although a larger study population is need to better delineate our hypothesis.

\section{Limitations}

The small sample size of the current study is a limitation, but the numerosity depends also on the "rare" condition of re-operative isolated mitral valve patient.

\section{Acknowledgments}

Authors acknowledge AOR San Carlo Hospital, Basilicata, Italy, Cardiovascular Department staff.

Funding: None.

\section{Footnote}

Reporting Checklist: The authors have completed the STROBE reporting checklist. Available at https://dx.doi. org/10.21037/jtd-21-667

Data Sharing Statement: Available at https://dx.doi. org/10.21037/jtd-21-667

Peer Review File: Available at https://dx.doi.org/10.21037/ jtd-21-667

Conflicts of Interest: All authors have completed the ICMJE uniform disclosure form (available at https://dx.doi. org/10.21037/jtd-21-667). The authors have no conflicts of interest to declare.

Ethical Statement: The authors are accountable for all aspects of the work in ensuring that questions related to the accuracy or integrity of any part of the work are appropriately investigated and resolved. The Regional Unique Ethical Committee approved the use of these data for research (CEUR Registry Number 652021, ID 20210028661, approval received in data 20/07/2021). All participants gave informed consent before taking part in the study. This study conformed to the provisions of the Declaration of Helsinki (as revised in 2013).

Open Access Statement: This is an Open Access article distributed in accordance with the Creative Commons Attribution-NonCommercial-NoDerivs 4.0 International License (CC BY-NC-ND 4.0), which permits the noncommercial replication and distribution of the article with the strict proviso that no changes or edits are made and the original work is properly cited (including links to both the formal publication through the relevant DOI and the license). See: https://creativecommons.org/licenses/by-nc-nd/4.0/.

\section{References}

1. Onnasch JF, Schneider F, Falk V, et al. Minimally invasive approach for redo mitral valve surgery: a true benefit for the patient. J Card Surg 2002;17:14-9.

2. Casselman F, Aramendi J, Bentala M, et al. Endoaortic Clamping Does Not Increase the Risk of Stroke in Minimal Access Mitral Valve Surgery: A Multicenter 
Experience. Ann Thorac Surg 2015;100:1334-9.

3. Launcelott S, Ouzounian M, Buth KJ, et al. Predicting in-hospital mortality after redo cardiac operations: development of a preoperative scorecard. Ann Thorac Surg 2012;94:778-84.

4. Daemen JHT, Heuts S, Olsthoorn JR, et al. Right minithoracotomy versus median sternotomy for reoperative mitral valve surgery: a systematic review and meta-analysis of observational studies. Eur J Cardiothorac Surg 2018;54:817-25.

5. Stone GW, Adams DH, Abraham WT, et al. Clinical Trial Design Principles and Endpoint Definitions for Transcatheter Mitral Valve Repair and Replacement: Part 2: Endpoint Definitions: A Consensus Document From the Mitral Valve Academic Research Consortium. J Am Coll Cardiol 2015;66:308-21.

6. Botta L, Cannata A, Bruschi G, et al. Minimally invasive approach for redo mitral valve surgery. J Thorac Dis 2013;5 Suppl 6:S686-93.

7. Yamazaki M, Yoshitake A, Takahashi T, et al. Superior trans-septal approach for minimally invasive mitral valve surgery via right small thoracotomy. J Card Surg 2019;34:728-31.

8. Savage EB, Ferguson TB Jr, DiSesa VJ. Use of mitral valve repair: analysis of contemporary United States experience reported to the Society of Thoracic Surgeons National Cardiac Database. Ann Thorac Surg 2003;75:820-5.

9. Nishimura RA, Otto CM, Bonow RO, et al. 2017 AHA/ ACC Focused Update of the 2014 AHA/ACC Guideline for the Management of Patients With Valvular Heart Disease: A Report of the American College of Cardiology/ American Heart Association Task Force on Clinical Practice Guidelines. Circulation 2017;135:e1159-95.

10. Baumgartner H, Falk V, Bax JJ, et al. 2017 ESC/EACTS Guidelines for the management of valvular heart disease. Eur Heart J 2017;38:2739-91.

11. Thompson MJ, Behranwala A, Campanella C, et al. Immediate and long-term results of mitral prosthetic replacement using a right thoracotomy beating heart technique. Eur J Cardiothorac Surg 2003;24:47-51; discussion 51.

12. Salhiyyah K, Taggart D. Beating-heart valve surgery: A systematic review. Asian Cardiovasc Thorac Ann 2009; 17:650-8.

13. Wang J, Liu H, Xiang B, et al. Keeping the heart empty and beating improves preservation of hypertrophied hearts for valve surgery. J Thorac Cardiovasc Surg 2006;132:1314-20.
14. Turer AT, Hill JA. Pathogenesis of myocardial ischemiareperfusion injury and rationale for therapy. Am J Cardiol 2010;106:360-8.

15. Wang J, Liu H, Salerno TA, et al. Does normothermic normokalemic simultaneous antegrade/retrograde perfusion improve myocardial oxygenation and energy metabolism for hypertrophied hearts? Ann Thorac Surg 2007;83:1751-8.

16. Wang J, Liu H, Salerno TA, et al. Does normothermic normokalemic simultaneous antegrade/retrograde perfusion improve myocardial oxygenation and energy metabolism for hypertrophied hearts? Ann Thorac Surg 2007;83:1751-8.

17. Botta L, Cannata A, Bruschi G, et al. Beating heart mitral valve surgery: innovation or back to the past? J Card Surg 2010;25:318; author reply 318-9.

18. Binder RK, Webb JG. Percutaneous mitral and aortic paravalvular leak repair: indications, current application, and future directions. Curr Cardiol Rep 2013;15:342.

19. Rival PM, Moore THM, McAleenan A, et al. Transthoracic clamp versus endoaortic balloon occlusion in minimally invasive mitral valve surgery: a systematic review and meta-analysis. Eur J Cardiothorac Surg 2019;56:643-53.

20. Hiraoka A, Kuinose M, Totsugawa T, et al. Mitral valve reoperation under ventricular fibrillation through right mini-thoracotomy using three-dimensional videoscope. J Cardiothorac Surg 2013;8:81.

21. Murzi M, Miceli A, Di Stefano G, et al. Minimally invasive right thoracotomy approach for mitral valve surgery in patients with previous sternotomy: a single institution experience with 173 patients. J Thorac Cardiovasc Surg 2014;148:2763-8.

22. Arcidi JM Jr, Rodriguez E, Elbeery JR, et al. Fifteenyear experience with minimally invasive approach for reoperations involving the mitral valve. J Thorac Cardiovasc Surg 2012;143:1062-8.

23. Seeburger J, Borger MA, Falk V, et al. Minimally invasive mitral valve surgery after previous sternotomy: experience in 181 patients. Ann Thorac Surg 2009;87:709-14.

24. Ricci D, Pellegrini C, Aiello M, et al. Port-access surgery as elective approach for mitral valve operation in re-do procedures. Eur J Cardiothorac Surg 2010;37:920-5.

25. Imran Hamid U, Digney R, Soo L, et al. Incidence and outcome of re-entry injury in redo cardiac surgery: benefits of preoperative planning. Eur J Cardiothorac Surg 2015;47:819-23.

26. Bilal RH, Keenan D. Role of computed tomography in 
tailoring reoperative procedures and changing trends in reoperative cardiac surgery. Eur J Cardiothorac Surg 2015;47:824-5.

27. Ramchandani M, Al Jabbari O, Abu Saleh WK, et al. Cannulation Strategies and Pitfalls in Minimally Invasive Cardiac Surgery. Methodist Debakey Cardiovasc J 2016;12:10-3.

28. Mehaffey HJ, Hawkins RB, Schubert S, et al.

Cite this article as: Prestipino F, D'Ascoli R, Nagy Á, Paternoster G, Manzan E, Luzi G. Mini-thoracotomy in redo mitral valve surgery: safety and efficacy of a standardized procedure. J Thorac Dis 2021;13(9):5363-5372. doi: 10.21037/ jtd-21-667
Contemporary outcomes in reoperative mitral valve surgery. Heart 2018;104:652-6.

29. Finks JF, Osborne NH, Birkmeyer JD. Trends in hospital volume and operative mortality for high-risk surgery. $\mathrm{N}$ Engl J Med 2011;364:2128-37.

30. Cohn LH. Evolution of redo cardiac surgery: review of personal experience. J Card Surg 2004;19:320-4. 